\title{
Basic provisions for the analytical calculation of vertical cylindrical containers
}

\author{
Oleksandr Lapenko ${ }^{1}$, Natalia Makhinko² \\ National Aviation University \\ Cosmonaut Komarov avenue 1, Kyiv, Ukraine, 03058 \\ 1my-partner@ukr.net, orcid.org/0000-0002-2029-0792 \\ 2pasargada1985@gmail.com, orcid.org/0000-0001-8120-6374 \\ Received on 04.03.2019, accepted after revision on 03.12.2019 \\ https://doi.org/10.32347/uwt2020.10.1801
}

\begin{abstract}
The basic provisions for the analytical calculation of vertical cylindrical capacities are provided in this article. The submitted data is the result of a global study accomplished by the authors in recent years. The simplified procedure of mathematical calculations, which is used in the formulation of these dependencies, can characterize the outlined aspects in line with the engineering method and be recommended for practical application. In the given research the problem of the influence of profiling of the wall of the vessel on the radial movements of the case under the action of axially asymmetric and asymmetric loading is analyzed. The basic calculation formulas are given for determination of internal forces (ring normal stresses, running bending moments and running transverse forces) and displacements of the nogauge storage capacity under load, which is described by the exponential law characteristic of the pressure of the loose material. A brief description of the influence of vertical ribs on the rigidity characteristics of silo tanks, as well as the expressions for estimating longitudinal forces in the ribs at a certain altitude level is given. Particular attention is given to the calculation of cylindrical capacities under conditions of asymmetrical radial loading.
\end{abstract}

In this case, the problem is considered for two variants of the simplified procedure, in accordance with the instantaneous theory and a more precise analytical solution in applying the equilibrium equations of the moment theory, which allows taking into account the effect of internal bending moments in the sections. In both cases, the simplification of the computational procedure is accom-

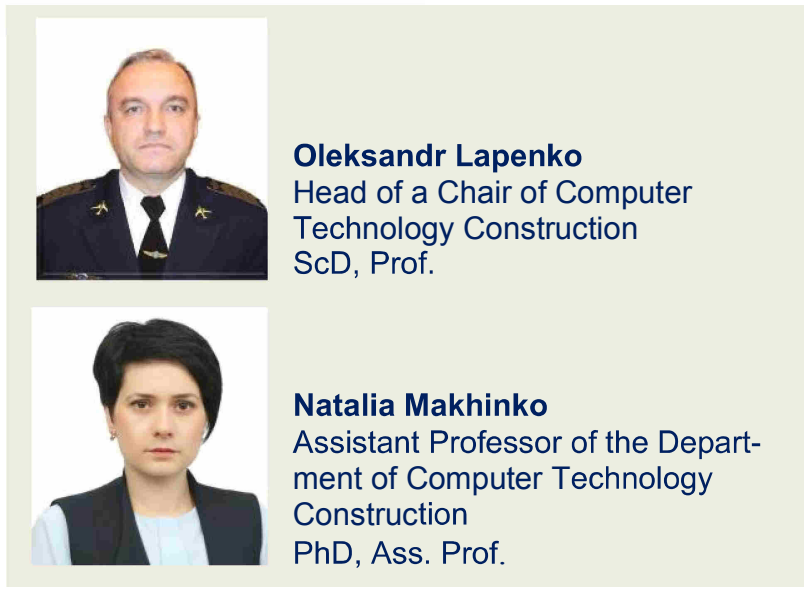

plished by decomposing an asymmetric load into a finite trigonometric series and conducting a calculation for each component separately. The internal forces arising in the edges of the conical roofs from the action of the most probable loads own weight, weight of technological equipment, wind pressure and snow load are also calculated. In this case, only the simplest construction of the roof was considered, characteristic of small diameter containers, which consist exclusively of the main radial edges. The article provides the formulas for finding the internal forces in this element and the maximum compressive force and maximum bending moment in a dangerous section.

Keywords: cylindrical shell, displacements, corrugated wall, exponential law, deflection functions, stress state, vertical stiffeners, axisymmetric load, radial deflection. 


\section{INTRODUCTION}

Our country is one of the key players in the sector of production and export of grain crops. In this process, the most important technological operation is the processing and storage of grain, requiring the availability of appropriate complexes, which should provide the necessary conditions for the quality maintenance of seeds. The advantage in this segment is given to industrial metal capacities of different structural form (Fig.1). The basic requirements for this type of structures are based on general technical characteristics of strength, rigidity and stability, as well as economic feasibility.

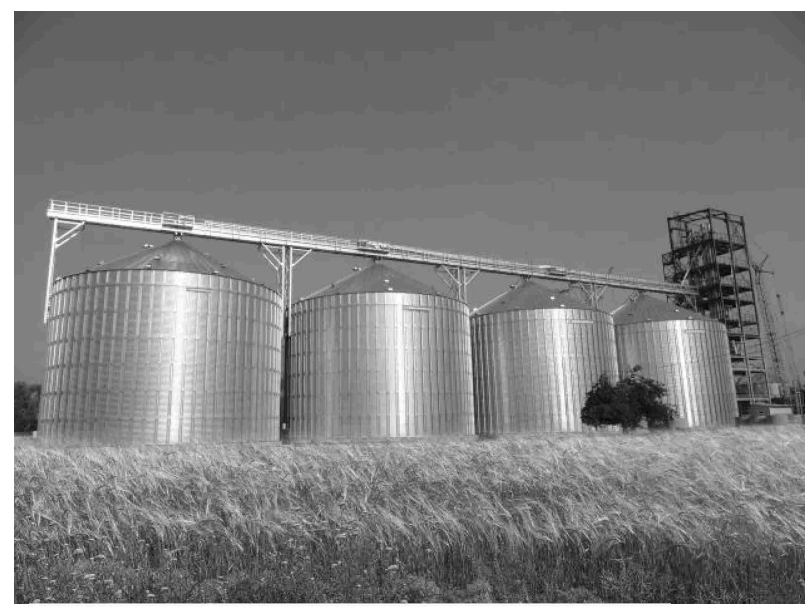

Fig. 1. General view of the vertical steel cylindrical containers of "Lubnymash" (https://lubnymash.com/)

Modern steel containers for storage of grain crops have taken leading positions in the elevator market. Despite a rather long period of production and operation of buildings of this type, the calculation of their supporting structural elements and a comprehensive study of their general characteristics have not received sufficient development till now.

\section{MATERIALS AND METHODS}

The analysis of the stress-strain state of steel in cylindrical silos tanks is a complex engineering task that requires significant scientific effort and knowledge; it is based on the use of special software groups and complicat- ed mathematical apparatus for computing $[1-5]$. The purpose of the calculation is the unambiguous definition of the stress-strain state of the container from the action of the most probable loads the vertical and horizontal pressures of the loose material, which causes the axially symmetric loading and the pressure of the wind pressure, which applies asymmetric loads [6,7]. This is the most accurate method for determining the full range of internal efforts and displacements is the finite element method, which is recommended for use in practical calculations. However, there is often a need for an analytical calculation, which allows not only to quickly evaluate some project decisions, but also to formulate conditions for related tasks, weakly dependent on inaccuracies of formulas. For example, we can give the task of calculating the minimum weight or maximum reliability. In addition, the results obtained are a guide for the designer, which will allow to avoid technical errors or possible inaccuracies in the construction of FEM computer model in the future.

\section{RESULTS AND DISCUSSION}

Steel vertical cylindrical container is a rotation shell, which is supported by vertical ribs of stiffness. The thickness of the plates, from which the body of the container is tiled, varies in height, and the texture of the plates can be both smooth and wavy.

A comparative analysis of the resistance to deformation of profiled sheets [8-10] showed that with increasing thickness of the sheets, their rigidity characteristics deteriorate. With the classic bend of thin plates that work as membranes, the use of profiled sheets is more effective. However, with axially symmetric loading of the cylindrical shell of rotation with evenly distributed loads, which causes both tensile strength and compression forces, sheet profiling does not affect the radial displacement of the construction.

With asymmetric loading, sheet profiling reduces radial movements of the shell. This phenomenon is most pronounced for thin sheets with more "frequent" wave steps. 
Determination of internal forces and displacements of a cylindrical thin-walled shell at various boundary conditions is given in many scientific and reference sources, but the practical analytical calculation is complicated by the search for a solution in loaded state, which is described by the exponential law, characteristic for the pressure of the loose material.

Dependences for internal forces and displacements for small-diameter capacities that do not have edges under load adopted by the Jansen-Kenen formula are expressed in terms of equation

$$
\begin{gathered}
w(x)=w_{0} \alpha e^{x s_{w}}\left\{1-e^{-k_{w} x} \times\right. \\
\times\left[\sin \left(k_{w} x\right)+\cos \left(k_{w} x\right)\right],
\end{gathered}
$$

where $w(x)$ is the function of moving of the shell; $w_{0}$ is the entered designation for this expression; $k_{w}$ is the ratio that can be defined by the formula

$$
k_{w}^{4}=E t_{e f, r} /\left(D_{w}^{2} D_{r}\right)
$$

where $t_{e f, r}=t_{w} \ell_{w, 1} / \ell_{w}$ is the thickness of the sheets (the rigidity of which is equivalent to the rigidity of the corrugated profile by thickness $\left.t_{e f}\right) ; \ell_{w, 1}$ is the length of the scanning of the corrugation in the waveform of the corrugated sheet of the shell $\ell_{w} ; E$ is the module of elasticity of the material; $D_{r}$ is the cylindrical rigidity of the shell on the bend in the circular direction; $D_{w}$ is the diameter of the shell.

Assessment of internal forces (circular normal stresses $\sigma_{h}$, geared bending moments $M_{x}(x)$ and running transverse forces $Q_{x}(x)$ ) Can be made by classical ratios [11 - 14]

$$
\begin{gathered}
\sigma_{h}(x)=2 w(x) \frac{E}{D_{w}}, \\
M_{x}(x)=-D_{r} \frac{d^{2} w(x)}{d x^{2}}, \\
Q_{x}(x)=\frac{d M_{x}(x)}{d x}=-D_{r} \frac{d^{3} w(x)}{d x^{3}} .
\end{gathered}
$$

The impact of vertical ribs on the rigidity characteristics of silo storage for grain depends on many factors [15 - 18].

With asymmetric loading and a small number of vertical edges, the value of the deflections is much smaller than that of non-rebound containers. In profiled shells it is more pronounced than flat ones (Fig. 2).

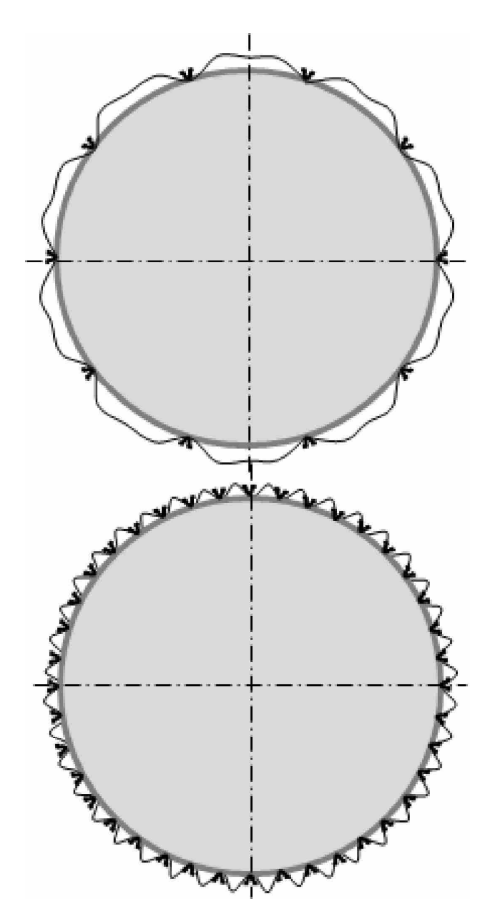

Fig. 2. Character of deformation of capacities from profiled sheets with different degrees of vertical stiff ribs and axisymmetric loading

Under the influence of an asymmetric load, the efficiency of vertical edges increases, especially with a sufficiently large number of them.

To evaluate the longitudinal force $N_{p}$ in each edge at the level $z$ from the top of a cylindrical container, with axial-symmetric loading we can use the expression

$$
\begin{gathered}
N_{p, z}=\frac{\pi D_{w}^{2}}{4 n_{p}}\left[g_{m}+S_{m}+\gamma_{g} H_{w} \psi_{y, 1}(y)\right], \\
\psi_{y, 1}=y\left(1-\left(1-e^{-\Delta_{y}}\right) / \Delta_{y}\right)
\end{gathered}
$$


where $g_{m}$ is the proper weight of the roof; $n_{p}$ is the number of vertical edges; $S_{m}$ is the snow load; $\Delta_{y}=4 \Delta_{w} \lambda_{0} f_{g} y$ is the dimensionless parameter determined by dimensionless height $y=z / H_{w}$, which has an area of values $0 \leq y \leq 1$.

If you analyze the value of the ratio of lateral pressure $\lambda_{0}$ and the ratio of friction $f_{g}$, then you can see that the values $\lambda_{0} f_{g}$ are in a fairly narrow range from $0,18 \ldots$ to 0,19 . Accordingly, it allows to adopt a unified value $\lambda_{0} f_{g} \approx 0,2$ and essentially simplify the expression $\Delta_{y} \approx 0,8 \Delta_{w} y$.

Vertical pressure $p_{f, z}$ on the wall of the tank at the level $y$ from friction material

$$
\begin{aligned}
& p_{f, z}=0,2 \gamma_{g} D_{w} \psi_{y, 2}(y)= \\
& =0,2 \gamma_{g} H_{w}\left[y-\psi_{y, 1}(y)\right], \\
& \psi_{y, 2}(y)=1,25\left(1-e^{-\Delta_{y}}\right) .
\end{aligned}
$$

The value of the functions $\psi_{y, 1}(y)$ and $\psi_{y, 2}(y)$ for capacities of different elongation were calculated in [19].

Procedure for estimating the bending moment $M_{p}$ in the vertical edges of the stiffness of the silo tank can be performed using conditional eccentricity $e_{p, e f}$ which determines the position of the center of gravity of the reduced cross section of the vertical rigidity edge

$$
\begin{gathered}
e_{p, e f}=h_{p} k_{y} /\left(1+\alpha_{w p}\right), \\
\alpha_{w p}=A_{p} n_{p} /\left(\pi D_{w} t_{w}\right),
\end{gathered}
$$

where $\alpha_{w p}=A_{p} n_{p} /\left(\pi D_{w} t_{w}\right)$ is the ratio of the cross-sectional areas of all vertical stiffening ribs and the wall of the vessel.

Calculation of cylindrical capacitances under conditions of asymmetric radial loading, as in the case of axisymmetric loading, can be carried out in a simplified procedure, in accordance with the no-moment theory. A more precise analytical solution can be obtained in the case of equilibrium equations of moment theory, which allows taking into account the effect of internal bending moments in crosssections. The task of calculating cylindrical capacitance in both cases is reduced to the expansion of an asymmetric load into a finite trigonometric series and the calculation for each component separately. For wind load $W_{k}$ this will be a cosine-series of aerodynamic ratios $C_{a e r}(\varphi)$

$$
\begin{gathered}
C_{a e r}(\varphi)=a_{0}+a_{1} \cos (\varphi)+a_{2} \cos (2 \varphi)+\ldots \\
\ldots+a_{k} \cos (k \varphi)+\ldots+a_{m} \cos (m \varphi),
\end{gathered}
$$

where $A_{k}$ is the amplitude value $k$ component; $\varphi$ is the angle of attack that takes into account the direction of the wind; $a_{k}$ is the ratio of expansion.

In accordance with the momentary theory, the full efforts of the wind load will manifest themselves, depending on the number of $m$ members in the trigonometric series

$$
\begin{gathered}
S_{k}(x, \varphi)=k A_{k} x \sin (k \varphi), \\
N_{p, k}(x, \varphi)=k^{2} A_{k} x^{2} \cos (k \varphi) / D_{w}, \\
N_{h, k}(\varphi)=A_{k} D_{w} \cos (k \varphi) / 2 .
\end{gathered}
$$

And the displacement of the capacity from the load $W_{k}$ is determined on condition

$$
\begin{gathered}
\frac{\partial u(x, \varphi)}{\partial x}=\frac{k^{2} x^{2}}{E t_{w}} \frac{1}{D_{w}\left(1+\alpha_{w p}\right)} A_{k} \cos (k \varphi), \\
\frac{\partial v(x, \varphi)}{\partial \varphi}+w(x, \varphi)=0, \\
\frac{2}{D_{w}} \frac{\partial u(x, \varphi)}{\partial \varphi}+\frac{\partial v(x, \varphi)}{\partial x}=0 .
\end{gathered}
$$

where $u, v$ and $w$ is the longitudinal, circular and radial movement of the body.

For maximum displacement values (at $\varphi=0)$ we can use the formulas

$$
\begin{gathered}
u_{\max }=0,5 G_{H} \xi_{p} / \Delta_{w}, \quad w_{\Sigma, \max }=0,75 G_{H} \xi_{w} \\
\xi_{w}=\sum_{k=0}^{m} k^{4} a_{k}
\end{gathered}
$$


where $G_{H}=2 w_{p} H_{w}^{2} \Delta_{w}^{2} /\left[3\left(1+\alpha_{w p}\right) E t_{w}\right]$ is the conditional deflection; $w_{p}$ is the estimated value of the wind load.

Applying the moment theory, it is necessary to outline the basic variables of the method, which will include normal tensions $\sigma_{p, k}$ in the section of the capacity, tangent $\tau_{p, k}$ in the longitudinal and three basic displacements, longitudinal $u_{k}$, radial $w_{k}$ and the ring $v_{k}$. Lowering complex calculations, studied in detail in [20], we note the expressions for loads in cross-sections $\sigma_{p, k}(y, \varphi)$ and $\tau_{p, k}(y, \varphi)$

$$
\begin{aligned}
& \sigma_{p, k}(y, \varphi)=\frac{E}{\Delta_{w}^{2}} \Lambda_{w} \frac{\psi_{\sigma, k}(y)}{k^{2}\left(k^{2}-1\right)^{2}} \lambda_{\eta, k}^{2} a_{k} \cos (k \varphi) \\
& \tau_{p, k}(y, \varphi)=\frac{E}{\Delta_{w}^{3}} \Lambda_{w} \frac{\psi_{\tau, k}(y)}{k^{3}\left(k^{2}-1\right)^{2}} \lambda_{\eta, k}^{3} a_{k} \sin (k \varphi) \\
& \psi_{m, k}(y)=M_{1, k} \operatorname{chs}\left(y \lambda_{\eta, k}\right)+\cos \left(y \lambda_{\eta, k}\right) \times \\
& \times\left[M_{2, k} \exp \left(-y \lambda_{\eta, k}\right)+M_{3, k} \exp \left(y \lambda_{\eta, k}\right)\right],
\end{aligned}
$$

where $M_{1, k}, M_{2, k}$ i $M_{3, k}$ is the dimensionless capacitance reaction function; $\xi_{k, 0}$ is the proportionality factor, which has the dimension of the function $\xi_{k}(y)$ and takes into account the nature of harmonious loading $W_{k} ; \lambda_{\eta, k}$ is the response factor.

And also radial $w_{k}(y, \varphi)$, ring $v_{k}(y, \varphi)$ and longitudinal $u_{k}(y, \varphi)$ moving

$$
\begin{aligned}
& w_{k}(y, \varphi)=2 D_{w} \Lambda_{w} \frac{\left[1-\psi_{m, k}(y)\right]}{\left(k^{2}-1\right)^{2}} a_{k} \cos (k \varphi), \\
& v_{k}(y, \varphi)=2 D_{w} \Lambda_{w} \frac{\left[1-\psi_{m, k}(y)\right]}{k\left(k^{2}-1\right)^{2}} a_{k} \sin (k \varphi), \\
& u_{k}(y, \varphi)=\frac{D_{w}}{\Delta_{w}} \Lambda_{w} \frac{\psi_{u, k}(y)}{k^{2}\left(k^{2}-1\right)^{2}} \lambda_{\mu, k} a_{k} \cos (k \varphi)
\end{aligned}
$$

where $\Lambda_{w}$ is the ratio of capacity compliance.

Functions $\psi_{u, k}(y), \psi_{\sigma, k}(y)$ and $\psi_{\tau, k}(y)$ are similar in their mathematical nature to $\psi_{m, k}(y)$. Their formula representation depends on the variation of the boundary conditions of fixing each edge (Fig.3).

The total state is defined as the sum of stress-strain states influence, and it depends on

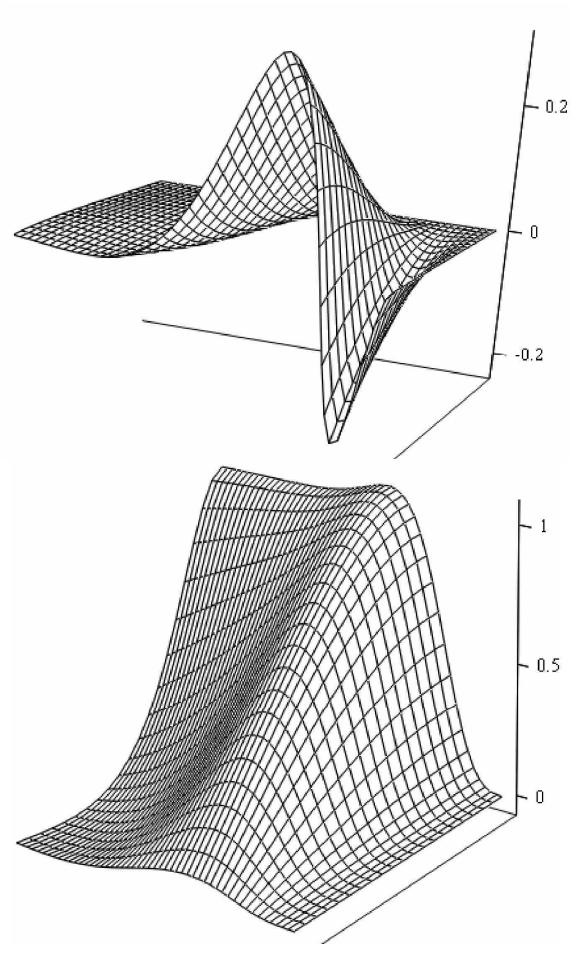

Fig. 3. Isometric representation of functions $\psi_{m, k}(y)$ and $\psi_{u, k}(y)$ for capacities with free end (top) and absolutely rigid ring (below)

the number of ratios of the layout laid down in the calculation

$$
R_{D}(y, \varphi)=\sum_{k=0}^{m} a_{k} R_{k}(y, \varphi)
$$

where $R$ is the generalized reaction parameter $R=\sigma_{p} \vee \tau \vee w \vee v \vee u$.

One of the essential steps in the calculation of vertical cylindrical tanks is the study of internal forces that arise in the edges of the conical roofs by the action of the most probable loads - own gravity, weight of process equipment, wind pressure and snow load (Fig. 4).

The construction of a conical roof of a cylindrical storage tank consists of rectilinear edges installed radially and connected by a series of rings that form a compatible spatial system. With relatively small diameters of capacities, radial ribs are made from beams, while large ones are in the form of trusses. In the case when the main radial edge is made in the 
form of trusses, the forces in its rods are calculated on the basis of beam effort. According to the principle of operation, radial edges can be divided into main and secondary. The main ribs, on one end, rely on the wall of the tank, reinforced by an elastic lining, and the other on the central rigid ring. Secondary ribs are placed between the main ones and are supported by one or both ends on the ring edges, hinged to the main radial beams.

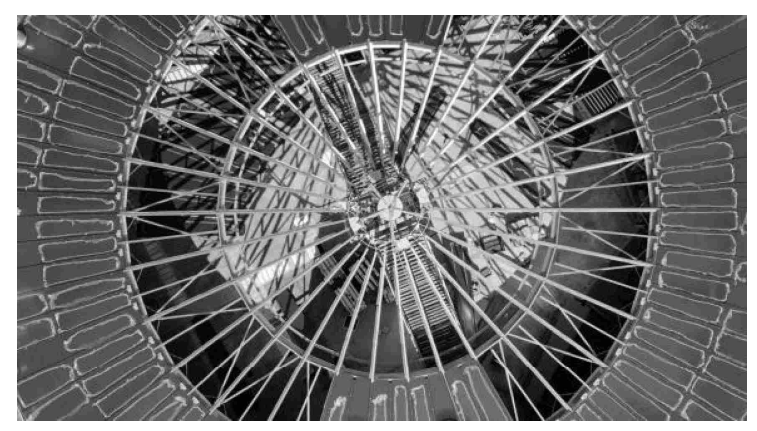

Fig. 4. Conical roofing of MSVU silo with a diameter of 33m "Lubnymash"

The simplest construction of the roof consists of only the main radial edges. A similar roof is characteristic for capacities of small diameter (approximately up to $7000 \mathrm{~mm}$ ) Internal forces in the main ribs can be calculated by the formulas.

$$
\begin{gathered}
N_{q, F}(y)=-\sin \beta\left[\frac{H_{A}}{\operatorname{tg} \beta}+F_{m}+q_{A} \ell_{M} y \times\right. \\
(\Delta q+0,5 y(1-\Delta q))+\Delta N], \\
Q_{q, F}(y)=q_{A} \ell_{M} \cos \beta[y \Delta q- \\
-\frac{1}{3}\left(\frac{1}{2}+\Delta q\right)+\frac{y^{2}}{2}(1-\Delta q)+\Delta Q, \\
M_{q, F}(y)=0,17 q_{A} \ell_{M}^{2} y \cos \beta(1-y) \times \\
\times[1+y(1-\Delta q)+2 \Delta q]+\Delta M .
\end{gathered}
$$

where $y$ is the coordinate; $g_{m}$ is the actual weight of the roof structures, $F_{m}$ is the force, from the weight of the thermopadders, $T_{m}$ is the reference pressure on the central ring of rigidity from the superstructure gallery, $S_{m}$ is the snow load; $W_{m}$ is the wind load; $n_{M}$ is the number of main beams; $\beta$ is the angle of the slope of the roof to the horizon; $\Delta_{D}$ is the ratio of the diameter of the central rigidity ring $d_{0}$ to the diameter of the tank $D_{w} ; \ell_{M}$ is the length of the main radial beams; $E A, E J$ is the longitudinal and flexural stiffness respectively; $\Delta N, \Delta Q, \Delta M$ is the arithmetical supplements of internal forces when placing a thermopaddings in the flight of a beam

The maximum compressive force acts on the left beam support, and the maximum bending moment in the section located at a distance $y_{M, \max }$ from the right support.

$$
\begin{gathered}
N_{M}=6 F_{m}+q \ell_{M}(1+2 \Delta q) /(6 \sin \beta), \\
M_{q, \max }=\frac{q_{A} \ell_{M}^{2} \cos \beta}{18}\left(\frac{2 f_{M}^{3}-3 f_{M}^{2}+1}{f_{M}^{2}-\Delta q}\right), \\
f_{M}=\sqrt{\left(1+\Delta q+\Delta q^{2}\right) / 3-\Delta f} .
\end{gathered}
$$

In the circular ribs there are only longitudinal compressive forces that can be estimated by the formula

$$
N_{p}=\left(N_{b}-N_{t}\right) n_{M} /(2 \pi) .
$$

where $N_{b}$ and $N_{t}$ are the longitudinal forces in the main radial edge below and above the annular rib of rigidity.

\section{CONCLUSIONS}

1. In the article the basic provisions of the analytical calculation of vertical cylindrical capacities were provided.

2. The issues of influence of profiling of the walls of the container on the radial movements of the case under the action of axially symmetric and asymmetric loading were analyzed.

3. The basic calculation formulas for the determination of internal forces and displacements of the ribless capacities under load, were described by the exponential law, characteristic for the pressure of the loose material.

4. The brief description of the influence of vertical ribs on the rigidity characteristics of silos capacities was given.. 
5. The calculation of cylindrical capacities in conditions of asymmetrical radial loading was solved in accordance with the instantaneous theory and has a more precise analytical solution in applying the equations of moment theory.

6. The formulas for finding internal forces in the edges of the conical roofs were indicated.

\section{REFERENCES}

1. Sukach M., 2017. Tretja mizhnarodna naukovo-praktychna konferencija Pidvodni tehnologiï. Underwater Technologies, Iss.06, 3-15 (in Ukrainian).

2. Song C.Y., 2004. Effects of patch loads on structural behavior of circular flat-bottomed steel silos. Thin-Walled Structures. Vol.42, No.11, 1519-1542.

3. Teng J.G., Lina X., Rotter J.M., Ding X.L., 2005. Analysis of geometric imperfections in full-scale welded steel silos. Engineering Structures. Vol.27, No.6, 938-950.

4. Iwicki P., Tejchman J., Chróścielewski J., 2014. Dynamic FE simulations of buckling process in thin-walled cylindrical metal silos. Vol.84, 344-359.

5. Gallego E., González-Montellano C., Ramírez A., Ayuga F., 2011. A simplified analytical procedure for assessing the worst patch load location on circular steel silos with corrugated walls. Engineering Structures. Vol.33, No.6, 1940-1954.

6. Brown C.J., Nielsen J., 2005. Silos: Fundamentals of Theory, Behaviour, and Design. E \& FN Spon, 837.

7. Sadowski A.J., 2017. Modelling of failures in thin-walled metal silos under eccentric discharge. Ph.D. dissertation, The University of Edinburgh, 128.

8. Lapenko O.I., Makhinko N., 2018. Vpliv profiljuvannja listiv na zhorstkisni harakteristiki yemnist dlja zberigannja zerna. Nauka ta budivnictvo, 40-45 (in Ukrainian).

9. Kachurenko V.V., Bannikov D.O., 2016. Konstruktivnyie resheniya stalnyih emkostey dlya syipuchih materialov. Novaya ideologiya, 168.

10. Rotter J.M., 2017. Structural and Functional Design of Metal Silos. CRC Press, 400.

11. Makhinko A., Makhinko N., 2018. Analysis of the deflective mode of thin-walled barrell shell. Academic journal. Industrial Machine Building, Civil Engineering, 69-78.

12. Goldenveyzer A.L., 1976. Teoriya uprugih tonkih obolochek. Nauka, 512.

13. Lessing E.N., Lileev A.F., Sokolov A.G., 1970. Listovyie metallicheskie konstruktsii. Stroyizdat, 490.

14. Segal A.I., 1951. Prakticheskie metodyi rascheta tonkostennyih konicheskih obolochek. Raschet prostranstvennyih konstruktsiy: sbornik statey. Vyp.2, 383-412.

15. Makhinko N., 2018. Vplyv vertykalnykh reber na zhorstkisni kharakterystyky sylosnykh yemnostei dlia zberihannia zerna. Visnyk «Lvivska politekhnika». Vol.888, 101-110 (in Ukrainian).

16. Topkaya C., Rotter J.M., 2014. Ideal Location of Intermediate Ring Stiffeners on Discretely Supported Cylindrical Shells. Journal of Engineering. Vol.140, No.4.

17. Zeybek Ö., Topkaya C., Rotter J.M., 2017. Requirements for intermediate ring stiffeners placed below the ideal location on discretely supported shells. Thin-Walled Structures, Vol.115, 21-33.

18. Wojcik M. Iwicki P., Tejchman J., 2011. 3D buckling analysis of a cylindrical metal bin composed of corrugated sheets strengthened by vertical stiffeners. Thin Walled Structures, Vol.49, No.8, 947-963.

19. Makhinko N., 2018. Rozrakhunok yemnostei z ploskym dnyshchem, yak obolonok obertannia zminnoi zhorstkosti. Visnyk Odeskoi derzhavnoi akademii budivnytstva ta arkhitektury. Vol.70, 68-74 (in Ukrainian).

20. Makhinko N., 2018. Stress-strain state of the storage silos under the action of the asymmetric load. Matec Web of Conference. Structures, Buildings and Facilities, Vol.230, 1-6.

\section{К расчету оптимального уровня надежности из экономических соображений}

\section{Александр Лапенко, Наталия Махинько}

Аннотация Приведены основные положения аналитического расчета вертикальных цилиндрических емкостей. Представленные сведения являются результатом глобального исследования, выполненного авторами в последние годы. Упрощенная процедура математических выкладок, которая применяется при формулировании указанных зависимостей, может 
характеризовать указанные аспекты в русле инженерной методики и быть применена для практических рекомендаций. В представленном исследовании анализируется влияние профилирования листов стенки емкости на радиальные перемещения корпуса при воздействии осесимметричного и асимметричного загрузки. Приводятся основные расчетные формулы для определения внутренних усилий (кольцевых нормальных напряжений, погонных изгибающих моментов и погонных поперечных сил) и перемещений безреберной емкости хранения. Предоставлена краткая характеристика влияния вертикальных ребер на жесткостных характеристики силосных емкостей, а также выражения для оценки продольных усилий в ребрах на определенном высотном уровне.

Особое внимание уделено расчету цилиндрических емкостей в условиях несимметричного радиального загрузки. При этом задача рассмотрена по упрощенной процедуре, согласно безмоментной теории и получено более точное аналитическое решение при применении уравнений равновесия моментной теории, которая позволяет учесть действие внутренних изгибающих моментов в сечениях. В обоих случаях выполнено упрощения вычислительной процедуры путем разложения асимметричной нагрузки в конечный тригонометрический ряд и проведении расчета для каждой составляющей в отдельности. Выполнены также исследования внутренних усилий, возникающих в ребрах конусных кровель от действия наиболее вероятных нагрузок. При этом была рассмотрена лишь простейшая конструкция кровли, характерная для емкостей малого диаметра, которая состоит исключительно из главных радиальных ребер. Указанные формулы для нахождения внутренних усилий в данном элементе, максимальная сжимающая сила и максимальный изгибающий момент в опасном сечении.

Ключевые слова: цилиндрическая оболочка, перемещения, гофрированная стенка, функции прогиба, напряженное состояние, вертикальные ребра жесткости, асимметричная нагрузка, радиальное отклонение. 